\title{
Breaking the Symmetry: Assembly of Cylindrical Nanostructures with a $C_{3}$-Symmetrical Ligand
}

\author{
Céline Olivier, Euro Solari, Rosario Scopelliti, and Kay Severin* \\ Institut des Sciences et Ingénierie Chimiques, Ecole Polytechnique Fédérale de Lausanne (EPFL), \\ CH-1015, Lausanne, Switzerland
}

Received March 27, 2008

The reaction of a tripodal ligand containing terminal 2,3-dihydroxypyridine groups with (arene)ruthenium(II) complexes resulted in the formation of cylindrical nanostructures.

Ligands with $C_{3}$ symmetry have been used extensively as building blocks in supramolecular coordination chemistry. By a combination with metal-based connectors, it is possible to obtain coordination cages. ${ }^{1}$ Most commonly, these cages have a tetrahedral, an octahedral, or a prismatic geometry (Scheme 1a), but more complex structures such as cuboctahedra, ${ }^{2}$ dodecahedra, ${ }^{3}$ trigonal antiprisms, ${ }^{4}$ interlocked cages,${ }^{5}$ or a double-walled tetrahedron ${ }^{6}$ have been reported as well. ${ }^{1}$ The rigidity of the ligand is a decisive parameter for the successful formation of coordination cages because smaller aggregates are entropically favored. As a result, flexible ligands prefer to form

* To whom correspondence should be addressed. E-mail: kay.severin@epfl.ch.

(1) (a) For reviews see: Maurizot, V.; Yoshizawa, M.; Kawano, M.; Fujita, M. Dalton Trans. 2006, 2750-2756. (b) Cronin, L. Angew. Chem., Int. Ed. 2006, 45, 3576-3578. (c) Kleij, A. W.; Reek, J. N. H. Chem.-Eur. J. 2006, 12, 4218-4227. (d) Amijs, C. H. M.; van Klink, G. P. M.; van Koten, G. Dalton Trans. 2006, 308-327. (e) Fiedler, D.; Leung, D. H.; Bergman, R. G.; Raymond, K. N. Acc. Chem. Res. 2005, 38, 349-358. (f) Fujita, M.; Tominaga, M.; Hori, A.; Therrien, B. Acc. Chem. Res. 2005, 38, 369-378. (g) Schmittel, M.; Kalsani, V. Top. Curr. Chem. 2005, 245, 1-53. (h) Albrecht, M.; Janser, I.; Fröhlich, R. Chem. Commun. 2005, 157-165. (i) Hamilton, T. D.; MacGillivray, L. R. Cryst. Growth Des. 2004, 4, 419-430. (j) Seidel, S. R.; Stang, P. J. Acc. Chem. Res. 2002, 35, 972-983. (k) Saalfrank, R. W.; Uller, E.; Demleitner, B.; Bernt, I. In Structure and Bonding; Fujita, M.), Ed.; Springer Verlag: Berlin, 2000; Vol. 96, pp 149-175. (1) Albrecht, M. Angew. Chem., Int. Ed. 1999, 38, 3463-3465. (m) Saalfrank, R. W.; Demleitner, B. In Perspectives in Supramolecular Chemistry; Sauvage, J.-P., Ed.; John Wiley \& Sons Ltd.: Chichester, U.K., 1999; Vol. 5, pp 1-51.

(2) Olenyuk, B.; Whiteford, J. A.; Fechtenkötter, A.; Stang, P. J. Nature 1999, 398, 796-799.

(3) Olenyuk, B.; Levin, M. D.; Whiteford, J. A.; Shield, J. E.; Stang, P. J. J. Am. Chem. Soc. 1999, 121, 10434-10435.

(4) (a) Saalfrank, R. W.; Glaser, H.; Demleitner, B.; Hampel, F.; Chowdhry, M. M.; Schünemann, V.; Truatwein, A. X.; Vaughan, G. B. M.; Yeh, R.; Davis, A. V.; Raymond, K. N. Chem.-Eur. J. 2002, 8, 493-497. (b) Johnson, D. W.; Xu, J.; Saalfrank, R. W. Raymond, K. N. Angew. Chem., Int. Ed. 1999, 38, 2882-2885.

(5) Fujita, M.; Fujita, N.; Ogura, K.; Yamaguchi, K. Nature 1999, 400, $52-55$.

(6) Oppel, I. M.; Föcker, K. Angew. Chem., Int. Ed. 2007, 47, 402-405.
Scheme 1. Structural Motifs of Coordination Compounds Based on $\mathrm{C}_{3}$-Symmetrical Ligands

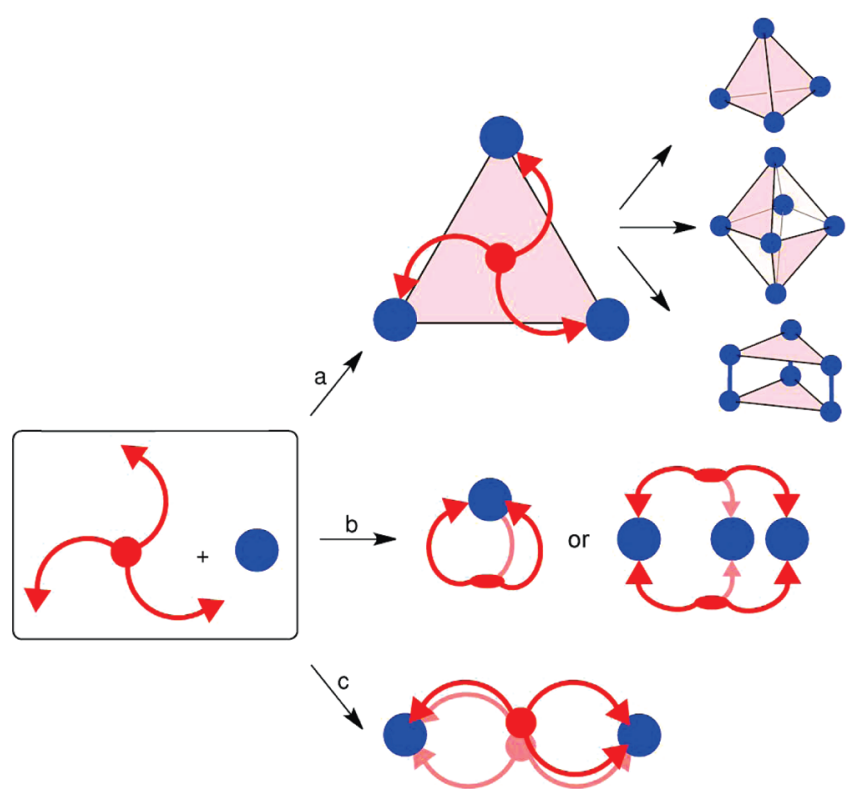

complexes with low nuclearity such as podates ${ }^{1 \mathrm{~h}, 7}$ or "trigonal boxes" ${ }^{\prime}$ (Scheme 1b). For most of the abovementioned structures, the $C_{3}$ symmetry of the ligand is, at least locally, preserved in the final supramolecular aggregate. Below, we describe a novel structural motif, which was obtained with a tripodal ligand containing terminal 2,3-dihydroxypyridine groups. When combined

(7) (a) For selected examples see: Albrecht, M.; Burk, S.; Stoffel, R.; Lüchow, A.; Fröhlich, R.; Kogej, M.; Schalley, C. A. Eur. J. Inorg. Chem. 2007, 1361-1372. (b) Pierre, V. C.; Botta, M.; Aime, S.; Raymond, K. N. J. Am. Chem. Soc. 2006, 128, 5344-5345. (c) Comby, S.; Imbert, D.; Chauvin, A.-S.; Bünzli, J.-C. G. Inorg. Chem. 2006, 45, 732-743. (d) Albrecht, M.; Janser, I.; Runsink, J.; Raabe, G.; Weis, P.; Fröhlich, R. Angew. Chem., Int. Ed. 2004, 43, 6662-6666. (e) Koeller, S.; Bernardinelli, G.; Bocquet, B.; Piguet, C. Chem.-Eur. J. 2003, 9, 1062-1074.

(8) (a) For selected examples see: Chen, C.-L.; Zhang, J.-Y.; Su, C.-Y. Eur. J. Inorg. Chem. 2007, 2997-3010. (b) Ikeda, A.; Yoshimura, M.; Udzu, H.; Fukuhara, C.; Shinkai, S. J. Am. Chem. Soc. 1999, 121, 4296-4297. (c) Van Calcar, P. M.; Olmstead, M. M.; Balch, A. L. Chem Commun. 1996, 2597-2598. (d) Chan, C.-K.; Cheung, K.-K.; Che, C.-M. Chem. Commun. 1996, 227-228. (e) Fujita, M.; Nagao, S.; Ogura, K. J. Am. Chem. Soc. 1995, 117, 1649-1650. 
with (arene)ruthenium(II) connectors, cylindrical nanostructures instead of cages were formed (Scheme 1c).

Over the last years, we and others have shown that the reaction of 2,3-dihydroxypyridine ligands with (arene)ruthenium(II) or (cyclopentadienyl)metal [metal = rhodium(III), iridium(III)] complexes results in the formation of trinuclear complexes. ${ }^{9}$ The trimers are thermodynamically very stable, but they still undergo exchange reactions. ${ }^{10}$ This characteristic prompted us to investigate whether they can be used as a structural motif for the construction of even larger aggregates (with the trimers acting as metal-based connectors). Recently, we have reported that this is indeed possible: when $C_{2}$-symmetrical bis(2,3-dihydroxypyridine) ligands were reacted with organometallic half-sandwich complexes, helical nanostructures were obtained. ${ }^{11}$ In these complexes, two pyridonate trimers were connected by three linear spacers. In an extension of this work, we have now explored the reaction of a $C_{3}$-symmetrical tris(2,3-dihydroxypyridine) ligand with (arene)ruthenium(II) complexes. On the basis of symmetry considerations, we anticipated that this should result either in the formation of capped trimers, which represent analogues of podates (Scheme 1b) or in the formation of large cage structures (Scheme 1a). Unexpectedly, the self-assembly process resulted in the formation of a novel type of structure, which is detailed below.

The synthesis of the tris(2,3-dihydroxypyridine) ligand 6 is described in Scheme 2. The $C_{3}$ symmetry is provided by a trisubstituted benzene core, which was introduced in the form of 1,3,5-triformylbenzene (5). The 2,3-dihydroxypyridine groups were linked to this central core by condensation with the primary amine 4 , followed by reduction of the resulting imine. The aminomethyl-substituted 2,3-dihydroxypyridine 4 was obtained in three steps. First a Mannich reaction between the commercially available 2,3-dihydroxypyridine (1) and dibenzylamine was performed to give $\mathbf{2}$. After protection with a tert-butyldimethylsilyl (TBDMS) group, the amine $\mathbf{4}$ was obtained by hydrogenation of $\mathbf{3}$. The ligand $\mathbf{6}$ was formed in a final deprotection step with boron trifluoride etherate. The crude material was then purified by reversed-phase high-performance liquid chromatography (the

(9) (a) Mimassi, L.; Cordier, C.; Guyard-Duhayon, C.; Mann, B. E.; Amori, H. Organometallics 2007, 26, 860-864. (b) Grote, Z.; Scopelliti, R.; Severin, K. J. Am. Chem. Soc. 2004, 126, 16959-16972. (c) Mimassi, L.; Guyard-Duhayon, C.; Rager, M. N.; Amori, H. Inorg. Chem. 2004, 43, 6644-6649. (d) Grote, Z.; Lehaire, M.-L.; Scopelliti, R.; Severin, K. J. Am. Chem. Soc. 2003, 125, 13638-13639. (e) Lehaire, M.-L.; Schulz, A.; Scopelliti, R.; Severin, K. Inorg. Chem. 2003, 42, 3576-3581. (f) Lehaire, M.-L.; Scopelliti, R.; Severin, K. Angew. Chem., Int. Ed. 2002, 41, 1419-1421. (g) Lehaire, M.-L.; Scopelliti, R.; Severin, K. Chem. Commun. 2002, 2766-2767. (h) Lehaire, M.-L.; Scopelliti, R.; Severin, K. Inorg. Chem. 2002, 41, 5466-5474. (i) Piotrowski, H.; Severin, K. Proc. Natl. Acad. Sci. 2002, 99, 4997-5000. (j) Piotrowski, H.; Hilt, G.; Schulz, A.; Mayer, P.; Polborn, K.; Severin, K. Chem.-Eur. J. 2001, 7, 3196-3208. (k) Piotrowski, H.; Polborn, K.; Hilt, G.; Severin, K. J. Am. Chem. Soc. 2001, 123, 2699-2700.

(10) (a) Grote, Z.; Scopelliti, R.; Severin, K. Eur. J. Inorg. Chem. 2007, 694-700. (b) Saur, I.; Scopelliti, R.; Severin, K. Chem.-Eur. J. 2006, 12, 1058-1066. (c) Saur, I.; Severin, K. Chem. Commun. 2005, 14711473. (d) Grote, Z.; Scopelliti, R.; Severin, K. Angew. Chem., Int. Ed. 2003, 42, 3821-3825.

(11) (a) Olivier, C.; Grote, Z.; Solari, E.; Scopelliti, R.; Severin, K. Chem. Commun. 2007, 4000-4002. (b) Grote, Z.; Bonazzi, S.; Scopelliti, R.; Severin, K. J. Am. Chem. Soc. 2006, 128, 10328-10383.
Scheme 2. Synthesis of Ligand $\mathbf{6}^{a}$
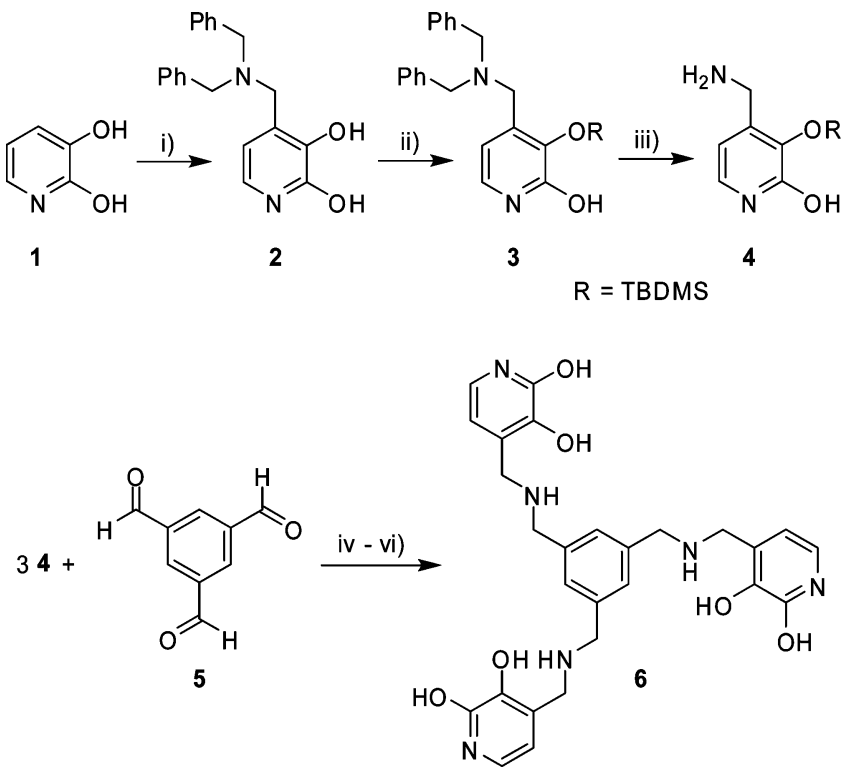

${ }^{a}$ Conditions: (i) $\mathrm{Bn}_{2} \mathrm{NH}, \mathrm{H}_{2} \mathrm{CO}, \mathrm{EtOH}, \Delta$; (ii) TBDMSCl, imidazole, DMF; (iii) $\mathrm{Pd} / \mathrm{C}, \mathrm{H}_{2}, \mathrm{MeOH}$; (iv) $\mathrm{MeOH}$; (v) $\mathrm{NaBH}_{4}, \mathrm{CHCl}_{3}$; (vi) $\mathrm{BF}_{3} \cdot \mathrm{Et}_{2} \mathrm{O}$, $\mathrm{CHCl}_{3}$.

\section{Scheme 3}

3

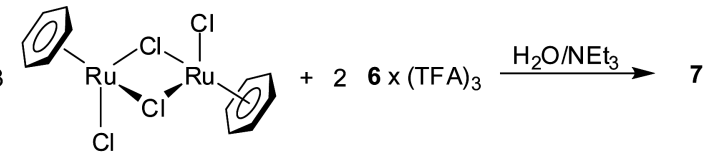

3

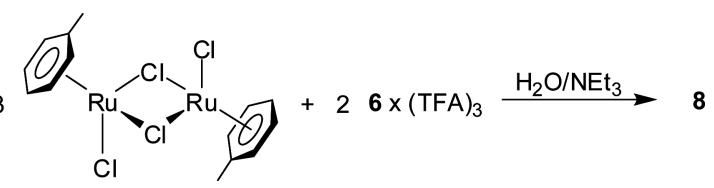

synthesis is described in detail in the Supporting Information).

The formation of trinuclear (arene)ruthenium(II) complexes is generally achieved by reacting the 2,3-dihydroxypyridine ligands with chloro-bridged half-sandwich complexes in the presence of a base. ${ }^{9}$ Following this general procedure, we have first dissolved ligand 6 (as the trifluoroacetic acid salt) with the dimers $\left[\left(\eta^{6}-\mathrm{C}_{6} \mathrm{H}_{6}\right) \mathrm{RuCl}_{2}\right]_{2}$ or $\left[\left(\eta^{6}-\right.\right.$ $\left.\left.\mathrm{C}_{6} \mathrm{H}_{5} \mathrm{Me}\right) \mathrm{RuCl}_{2}\right]_{2}$ in water. The $\mathrm{pH}$ of the solution was then slowly raised by vapor diffusion of $\mathrm{NEt}_{3}$. This led to the slow precipitation of complexes $\mathbf{7}$ and $\mathbf{8}$ in 57 and $52 \%$ yield, respectively (Scheme 3 ).

The complexes were found to be soluble in organic solvents such as $\mathrm{MeOH}$ or $\mathrm{CHCl}_{3}$. The ${ }^{1} \mathrm{H} \mathrm{NMR}$ spectra of 7 and 8 confirmed the expected 3:1 ratio of (arene)ruthenium to ligand 6. The spectra were surprisingly complex, however, with three sets of signals for the $\pi$ ligands and an apparent loss of $C_{3}$ symmetry for the bridging ligand (Figure 1).

The molecular weights of complexes 7 and 8 were determined by high-resolution mass spectrometry. The results indicated that both complexes are composed of six (arene)ruthenium fragments and two deprotonated ligands $\mathbf{6}$. Because these results were in conflict with any of the anticipated structures, we attempted to grow single crystals of $\mathbf{7}$ and $\mathbf{8}$. Suited crystals for a crystallographic analysis were obtained 


\section{COMMUNICATION}

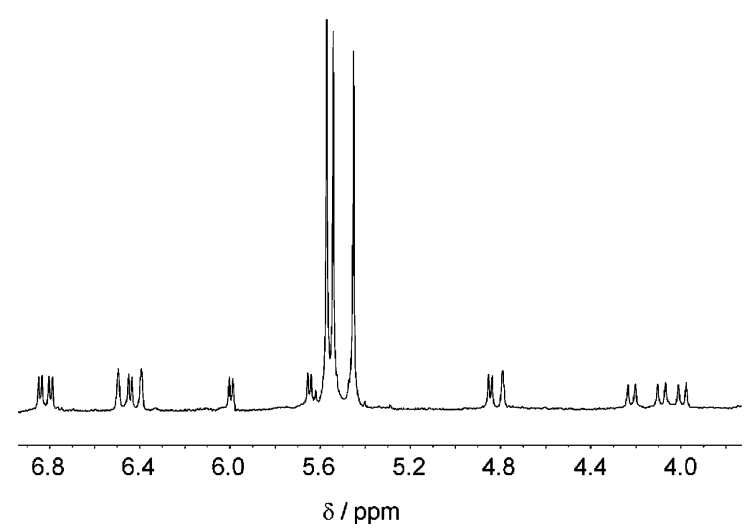

Figure 1. Part of the ${ }^{1} \mathrm{H}$ NMR spectrum $\left(\mathrm{CDCl}_{3}\right)$ of complex 7. The three singlets at $5.4-5.6 \mathrm{ppm}$ correspond to the benzene $\pi$ ligands. The remaining signals correspond to the aromatic $\mathrm{CH}$ protons of the bridging pyridonate ligands (six doublets for the pyridonate groups and three singlets for the central aromatic core).

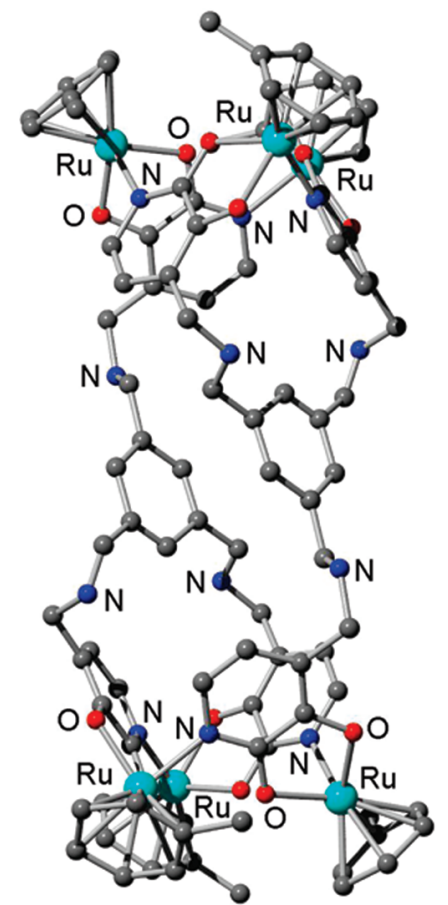

Figure 2. Molecular structure of complex $\mathbf{8}$ in the crystal. The cocrystallized water molecules and the $\mathrm{H}$ atoms are not shown for clarity.

for complex 8. As depicted in Figure 2, the complex is composed of two (toluene)ruthenium trimers, which are bridged by the tris(aminomethyl)benzene spacers. ${ }^{12}$ As a result, a cylindrical structure with a length of $24.7 \AA$ was observed (maximum $\mathrm{H}-\mathrm{H}$ distance). Significant amounts of water were found in the crystal $\left(\geq 18 \mathrm{H}_{2} \mathrm{O}\right.$ per complex). ${ }^{13}$

(12) (a) For a recent example of a Cu-based nanostructure, in which two metallamacrocycles are bridged by organic spacers, see: Gómez, L.; Company, A.; Fontrodona, X.; Ribas, X.; Costas, M. Chem. Commun. 2007, 4410-4412.

(13) A total of $18 \mathrm{H}_{2} \mathrm{O}$ molecules around the complex were identified in the refinement. The remaining electron density, which corresponds most likely to additional disordered water molecules, was treated with the "Squeeze" algorithm. See: Sluis, P. V. D.; Spek, A. L Acta Crystallogr., Sect. A 1990, 46, 194-201.
None of the water molecules reside in the interior of the cylinder, but several hydrogen-bond interactions with heteroatoms of the ligands were observed.

The geometries of the two trimeric (arene)ruthenium units in $\mathbf{8}$ are similar to what has been observed for other 2,3dihydroxypyridine-based trimers: the metal centers are bridged by the two adjacent $\mathrm{O}$ atoms and the $\mathrm{N}$ atom of the pyridine groups, resulting in a 12 -membered macrocycle. ${ }^{9}$ The average $\mathrm{Ru} \cdots \mathrm{Ru}$ distance within the trimeric unit is $5.4 \AA$; $\mathrm{Ru}$ atoms at the opposite end of the cylinder are on average 17.1 $\AA$ apart from each other. The two arene groups in the center of the structure are coplanar, and the distance of $3.8 \AA$ suggests favorable $\pi-\pi$ interactions.

Complex 8 has a crystallographic inversion center. Consequently, the three stereogenic Ru centers at one end of the cylinder have the opposite relative configuration to that of the three Ru centers at the other end of the cylinder. The NMR spectra of complex $\mathbf{8}$ in solution are in agreement with the structure determined by X-ray crystallography. The lack of additional signals points to the fact that the assembly of 8 (and by analogy of 7) proceeds in a highly diastereoselective fashion.

In view of the high yields and the long reaction times, we assumed that $\mathbf{7}$ and $\mathbf{8}$ were formed under thermodynamic control. This was substantiated by the fact that a solution of complex 8 in $\mathrm{CD}_{3} \mathrm{OD}$ does not show any additional ${ }^{1} \mathrm{H}$ NMR signals for rearranged complexes after tempering the solutions for $1 \mathrm{~h}$ at $50^{\circ} \mathrm{C} .{ }^{14}$

In conclusion, we have described the syntheses of two hexanuclear complexes, which were obtained by baseinduced assembly of (arene)ruthenium(II) complexes with the novel tris(2,3-dihydroxypyridine) ligand $\mathbf{6}$. The complexes display an unprecedented type of structure: they form a molecular cylinder with two terminal (arene)ruthenium trimers, which act as the connecting end groups for two ligands. The bridging ligands are no longer $C_{3}$-symmetric: two of the three arms are directed toward one end and the remaining arm toward the other end. Apparently, ligand $\mathbf{6}$ is too flexible to form a fully extended structure, as is required for the formation of a cage, but is still flexible enough to allow the partial back-folding of two arms. It will be interesting to see whether similar nanostructures can be obtained with other tripodal ligands.

Acknowledgment. This work was supported by the Swiss National Science Foundation and by the EPFL.

Supporting Information Available: X-ray crystallographic file (CIF) for complex 8 and experimental data for the synthesis of ligand $\mathbf{6}$ and complexes $\mathbf{7}$ and $\mathbf{8}$. This material is available free of charge via the Internet at http://pubs.acs.org.

\section{IC8005508}

(14) 2,3-Dihydroxypyridine-based trimers are known to undergo exchange reactions under these conditions (see ref 10). 